\title{
Significant decline of ecosystem service valuation and carbon stocks through changing land use patterns of Ayodhya hill range (extended part of Chhota Nagpur Plateau), India
}

\author{
Biswajit Bera ${ }^{1}$, Sumana Bhattacharjee ${ }^{2}$, Pravat Shit ${ }^{3}$, Nairita Sengupta ${ }^{4}$, and Soumik \\ Saha ${ }^{1}$ \\ ${ }^{1}$ Sidho-Kanho-Birsha University \\ ${ }^{2}$ Jogesh Chandra Chaudhuri College \\ ${ }^{3}$ Raja Narendra Lal Khan Women's College \\ ${ }^{4}$ Diamond Harbour Women's University
}

October 13, 2021

\begin{abstract}
Environment or natural capitals provide multiple ecosystem services (ESs) and benefits to people. The approach of ecosystem service values (ESVs) describes the market values of the ecosystem products or services. The changes of ecosystem service valuation and carbon stocks significantly dropped in Ayodhya hill range (extended part of Chhota Nagpur plateau of India) due to rapid land use modification. The principal objectives of this research are (i) to determine the spatiotemporal changing pattern of ESVs through different unit values (for the year 1975, 2000 and 2021) (ii) to analyze the carbon sequestration through InVEST carbon model and (iii) to assess gross primary product (GPP) using MOD17 model. The ESVs result shows that total ESVs over Ayodhya hill range are 256.67, 258.60 and 239.78 million USD for 1975, 2000 and 2021 respectively. Total 16.90 million USD loss has been observed over the study area during the overall study period. Cropland has the highest ESVs due to its high unit values along with high proportion of area. Total $1000759 \mathrm{mg}$ reduction of stored carbon has been estimated whereas a sharp decline of GPP (97.03 gC m-2 year-1) has also been observed during the research period (1975-2021). So, various integrated sustainable environmental management techniques should immediately apply over this nature based economic region for the benefits of local tribal people.
\end{abstract}

\section{Hosted file}

Manuscript.docx available at https://authorea.com/users/440950/articles/541579-significantdecline-of-ecosystem-service-valuation-and-carbon-stocks-through-changing-land-usepatterns-of-ayodhya-hill-range-extended-part-of-chhota-nagpur-plateau-india 

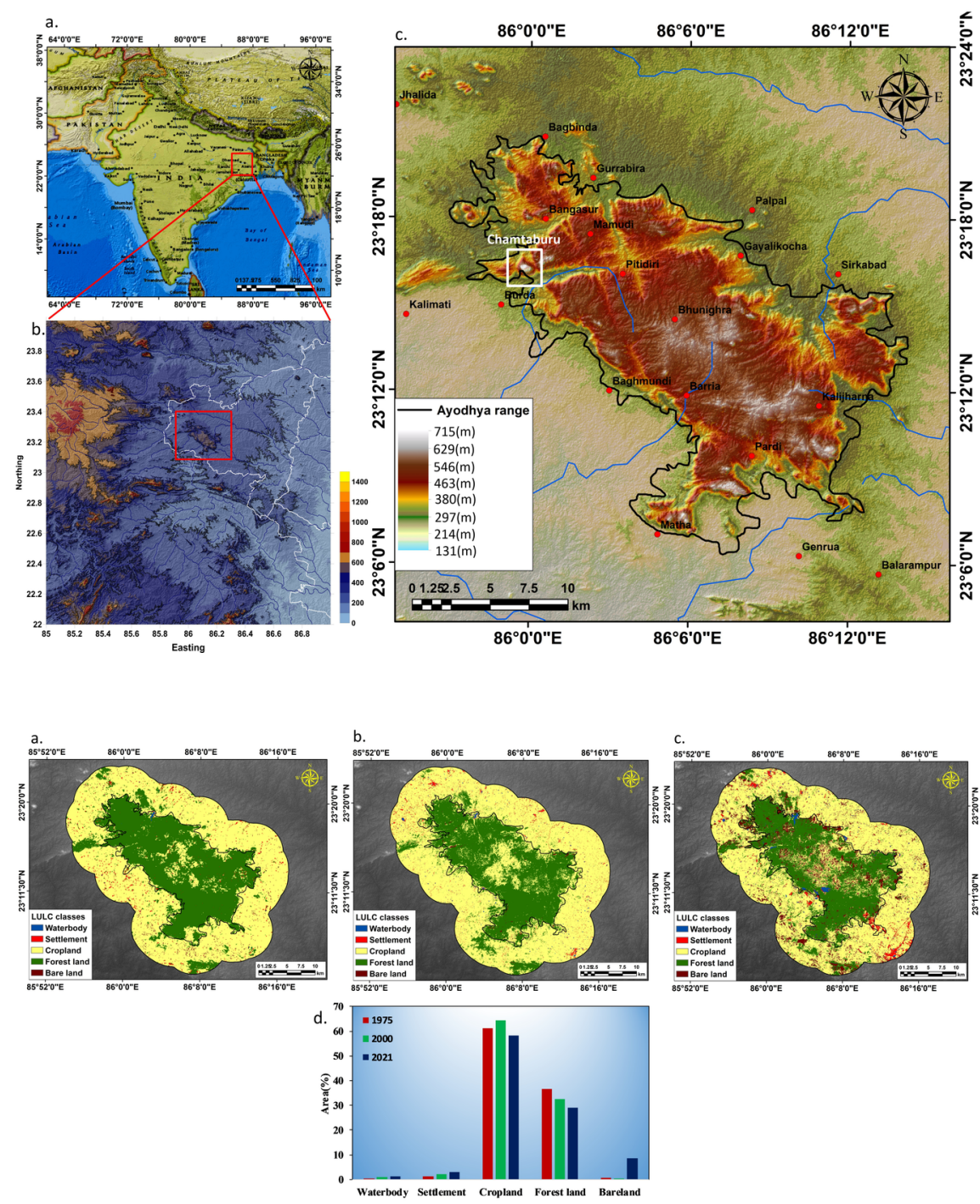

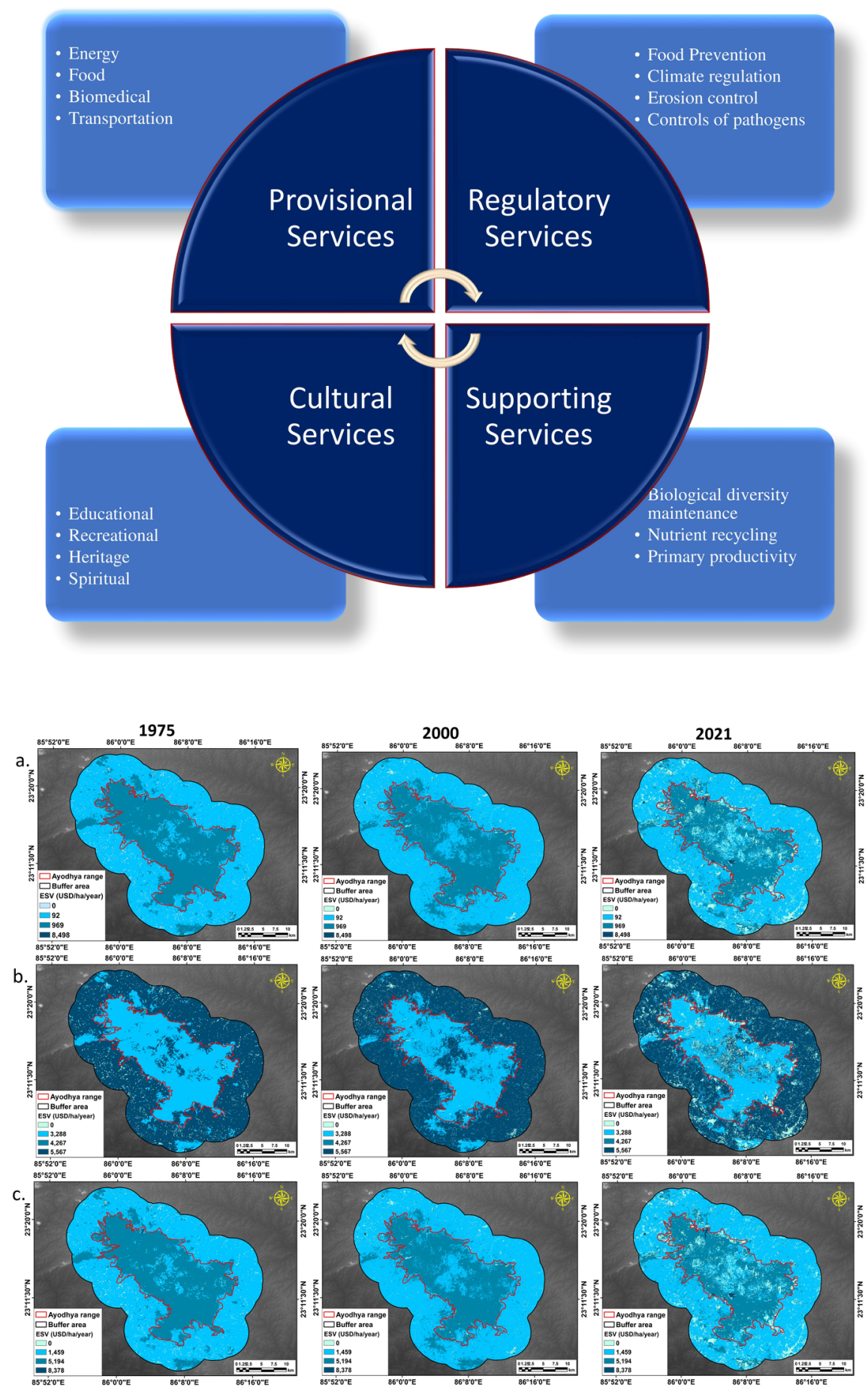

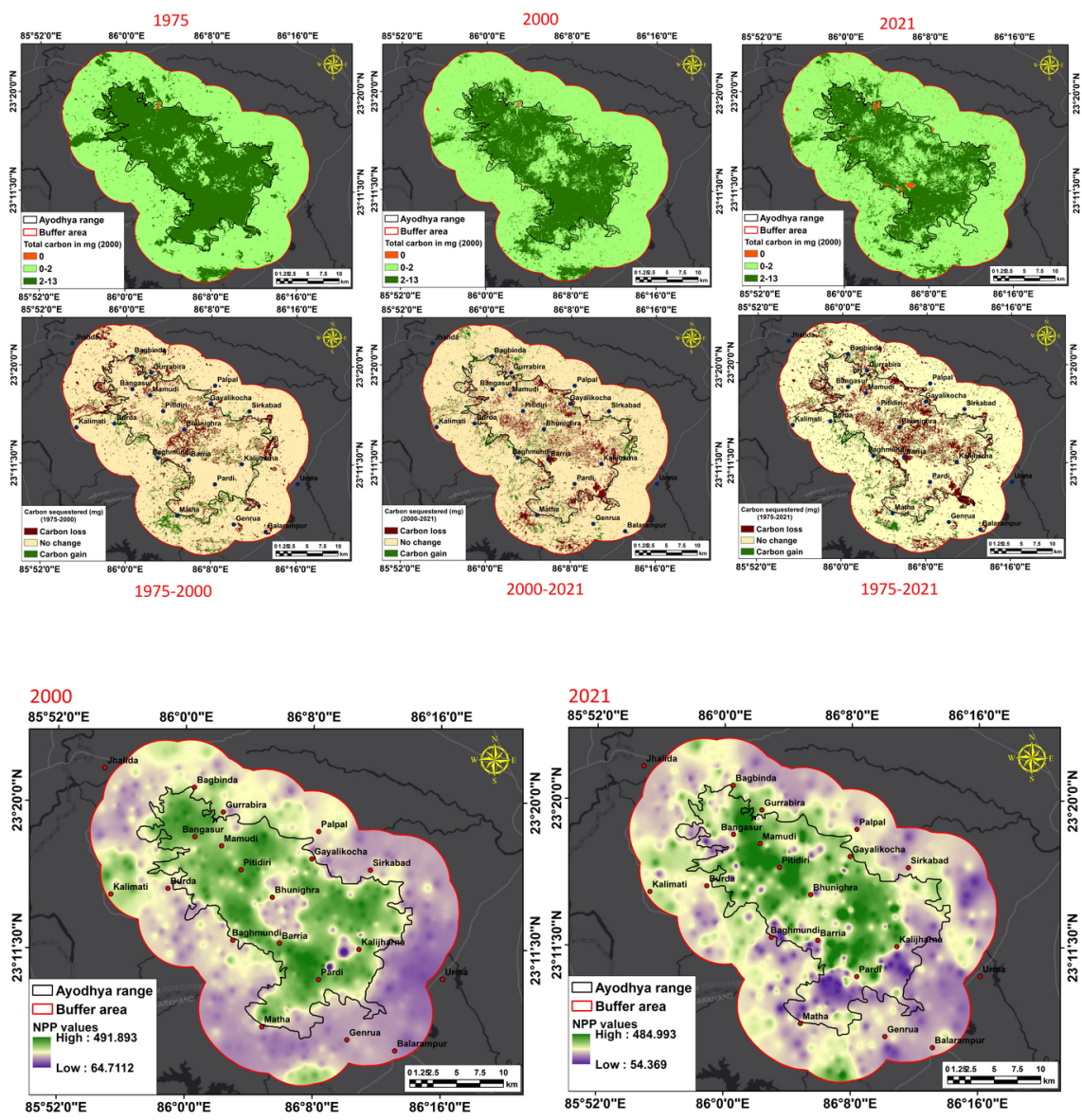